\title{
E-Business in Agriculture for Effective Communication between Merchants and Farmers
}

\author{
Ganesh Deshmukh \\ Professor \\ Computer Department \\ PCCOE \\ Pune, India \\ Vishwamohini Kumbhar \\ Computer Department \\ PCCOE \\ Pune, India
}

\author{
Kaushal Dhabadge \\ Computer Department \\ PCCOE \\ Pune, India
}

\author{
Neha Kuvlekar \\ Computer Department \\ PCCOE \\ Pune, India
}

\begin{abstract}
The Major Occupation in India is the Agriculture; the people involved in the Agriculture belong to the poor class and category. The people of the farming community are unaware of the new techniques and new arrivals in the agriculture departments, which would direct the world to greater heights in the field of agriculture. Though the farmers work hard, they are cheated by agents in today's market. Here, we have introduced a new concept for advanced, well-educated and interested farmers who are adopting latest technologies in farming. We are providing the facilities like guidance regarding market updates of different commodities, facilities and subsidies provided by Central and State Government, facilities and subsidies provided by merchants in India. Farmers are able to sale their goods (Crops, vegetables, fruits etc.)To the merchants giving the highest prize related to the product and the government authorizes person can watch all the transaction happened between the farmer and the merchant. The government has all the authority to see the transaction happened between merchants and farmers.
\end{abstract}

\section{Keywords}

Website, Market Rate, Data Mining, Weather forecasting, Elearning.

\section{INTRODUCTION}

The people of the farming community are unaware of the new techniques and new arrivals in the agriculture departments, which would direct the world to greater heights in the field of agriculture. Though the farmers work hard, they are cheated by agents in today's market. Now a days, world is like a global village due to computerization and internet facility. Here, we have introduced a new concept for advanced, welleducated and interested farmers who are adopting latest technologies in farming. There is no computerized system for the farmer to sell their product. Currently, the farmer goes to nearest market handover his product to a particular agent, agent ask the farmer to visit the market after a specific time to collect the cash earned out of the sold product. Every Agent tries to cuts his commission out of that. There is no way for farmer to know about the deal and the exact amount at which their product was sold. There is no transparency. No facility is present for the farmers to know the product rates at different markets where they can sell their products for achieving high profits. E-Agriculture will serve as a way for the farmers to sell their products across the country just with some basic knowledge about how to use the website. The site will guide

\author{
Ratnadeep Igave \\ Computer Department \\ PCCOE \\ Pune, India
}

the farmers in all the aspects such as the current market rate of different products, profit of the sold products, access to the new farming techniques through E-learning and centralized approach to view different government's agriculture schemes including the compensation schemes for farming. The main approach of this system is to prohibit the black marketing of the granary products. The government authorize person can view the whole transactions between the farmer and the Merchants. Getting availed to the required information related to the markets and different products can be made possible through the facility provided by the system.

\section{LITERATURE SURVEY}

In [1] authors proposed an android based mobile application Krishi Ville, This application will update different agriculture news, commodities and weather forecast updates. This paper focuses on rapid growth mobile telephony and introduction of new technologies in mobile information services which can play important role to overcome the existing information asymmetry. Use of mobile technology helps to bridge the gap between availability and delivery of agriculture inputs and infrastructure.

In [2] author describes the important role of Information Communication Technology in agricultural marketing. Paper focuses on improved record keeping related to agriculture using ICT for more detailed market strategies and cost analysis. Using ICT farmers can be connected with different facilities like rural banking, government schemes by providing farmers with unique identity card or e-passbook which is machine readable and have biometric access. ICT and Eagriculture will help in addressing many of challenges faced by Indian community and will help in uplifting the livehood of Indian farmers.

In [3] author describes that E-farming will serve as an efficient platform for Indian farmers to sell their product across country market with just basic knowledge of website. E-farming will help farmers to perform online agro-marketing leading to achieve good prices and increase their standard of living. E-agriculture website will also commodity wise, market wise updates to farmers in easy and interactive way.

\section{PROPOSED SYSTEM APPROACH}

E-Business in Agriculture for better communication between Merchants and Farmers is the web application that will help the farmers to perform the E- Business leading to achieve success and increase in their standard of living. E- Business in 
Agriculture will serve as a way for the farmers to sell their products across the country just with some basic knowledge about how to use the website. The main approach of this project is to prohibit the black marketing of the granary products. By using this system, farmer will get full profit of their product without bargaining with Merchants.

\subsection{Farmer's Module:}

E-farming will serve as a way for the farmers to sell their products across the country just with some basic knowledge about how to use the website. Farmers have to register themselves. Next step is to add the product he is willing to sell along with the product quantity and quality. Nearest merchant is searched by using knn algorithm. He is able to view all the prices availed by the merchants who are interested in buying the products. Farmers and merchants can send and accept request in order to carry out transactions.

\subsection{Merchant's Module:}

Merchants provide their prices for respective products based on the government base price. Validations are provided so that the merchants cannot enter the price value more or less than the government prices. He can view farmers and send request for carrying out the transaction. Firstly he should register as a merchant. After transaction all the details are available to the merchant as a proof.

\subsection{Government Module:}

Government is the admin of the system. He introduces base prices above which the merchants claim their prices which should not be very high. Farmers are able to view the government prices as well as the merchant's price. He can view all the transactions taking place between farmers and merchants based on apmc. He can daily change the base prices which are displayed to the farmer as well as merchant module. Due to this there is no scope of black-marketing. Whenever any transaction takes place between farmers and merchants all the details are displayed at the government module. He has record of all the transactions taking place in particular area.

\section{ALGORITHMS}

Farmers who want to perform marketing must have the login username and password the agent who will function the selling of farmer's product will be checked by the government committee for their marketing license and after approval, they will be granted with ID and password.

\subsection{PPKN Algorithm:-Privacy Preserving \\ $K$ nearest Algorithm}

This algorithm is used for searching result for inserted query. This algorithm helps to search the results.

The Algorithm's pseudo-code

Consider $\mathrm{k}$ as the desired number of nearest neighbour's and $\mathrm{S}$ : $=\mathrm{p}_{1}, \ldots \mathrm{p}_{\mathrm{n}}$ be the set of training samples in the form $\mathrm{p} 1=(\mathrm{xi}, \mathrm{ci})$, where $\mathrm{xi}$ is the $\mathrm{d}$-dimensional feature vector of the point pi and ci is the class that pi belongs to.

For each $\mathrm{p}^{\prime}=\left(\mathrm{x}^{\prime}, \mathrm{c}^{\prime}\right)$

- Compute the all pi belonging to $S$

distance $\mathrm{d}\left(\mathrm{x}^{\prime}, \mathrm{xi}\right)$ between $\mathrm{p}^{\prime}$ and

- Sort all points pi according to the key $\mathrm{d}\left(\mathrm{x}^{\prime}, \mathrm{xi}\right)$

- Select the first k points from the sorted list, those are the k closest training samples top'

- Assign a class top' based on majority vote: $\mathrm{c}^{\prime}=\operatorname{argmaxy} \sum(\mathrm{xi}, \mathrm{ci})$ belonging to $\mathrm{S}, \mathrm{I}(\mathrm{y}=\mathrm{ci})$

- $\quad$ End

\subsection{K-MEANS}

- K-means clustering is a method of vector quantization, originally from signal processing, that is popular for cluster analysis in data mining

- K- Means algorithm is used to make the group of the farmer and the merchant.

Step 1.

APMC market whose data is to be analysed is selected.

Step 2.

Data is to be clustered from selected APMC according to different crops available in that market.

Step 3.

$\mathrm{K}$-means algorithm generates $\mathrm{k}$ clusters from database. Where $\mathrm{k}$ is equal to the number of crops in database. i.e. if there are $n$ crops in database then $n$ clusters will be formed, such that each cluster contains data related to one crop.

Step 4.

For K-means algorithm $\mathrm{k}<\mathrm{d}$, Where $\mathrm{k}=$ number of clusters to be formed and $\mathrm{d}=$ number of data records.

\subsection{Apriori Algorithm}

- The Apriori Algorithm is an influential algorithm for mining frequent item sets for Boolean association rules. Apriori uses a "bottom up" approach, where frequent subsets are extended one item at a time (a step known as candidate generation, and groups of candidates are tested against the data.

- Apriori algorithm can be used to search whether particular farmer present in the dataset or not.

- When Farmer/Merchant wants to sell/buy crops then crop names will be selected by them.

Step 1. This set of crop names is used as the input to the apriori algorithm.

Step 2. Algorithm will check for the input set Records in database.

Step 3. If any record is found in database having all or any of the input record match then the entry that record is added to result array.

Step 4. Again next records are searched from database for match these records are entered in result array set.

Step 5. Same procedure is followed throughout until complete database is scanned.

Step 6. The result string now contains all the Farmers/ Merchants having crops similar to input string.

\section{PROPOSED ARCHITECTURE}

In our E-Business Agriculture for effective communication between Merchants and Farmers system there are mainly 3 modules Farmer, Merchant and Government. Farmer and Merchant have to register him. After Farmer login, Farmer can add products details i.e. crop income in quintal and after Merchant login, Merchant can add product price per quintal. System gives information of Merchant who gives best price to Farmer from nearest AMPC. Also system gives information of Farmer who sale the product which are purchase by particular active Merchant from nearest APMC. Government module has responsible to add products and its base price into the system. Government has an authority to view all Farmers and Merchants information in all APMC'S. Also he has authority 
to check transaction details of all Farmers and Merchants to stop black marketing

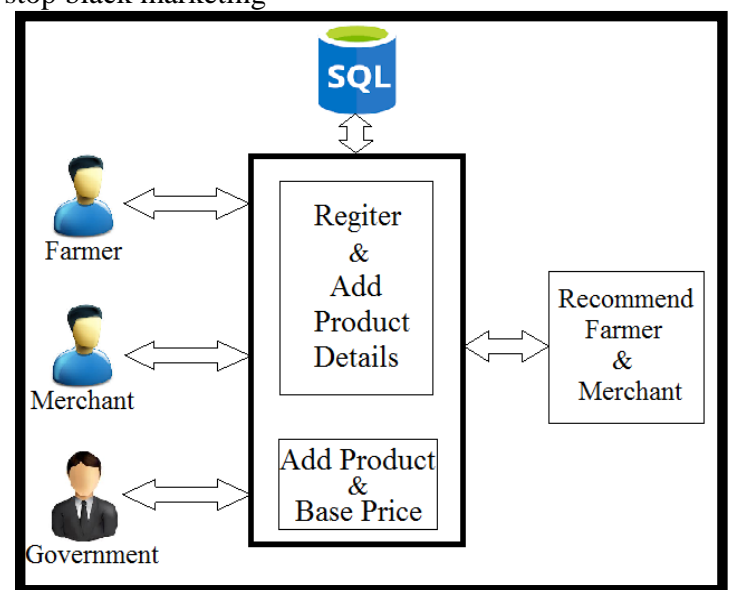

Fig. 1: System Architecture

\section{RESULTS AND DISCUSSIONS}

Base price of the crops is given by the government. It should be visible to farmers as well as merchants. The merchant claims their prices on the basis of the government prices. We encounter this page after registration. It also displays various information about temperature, weather and calendar.

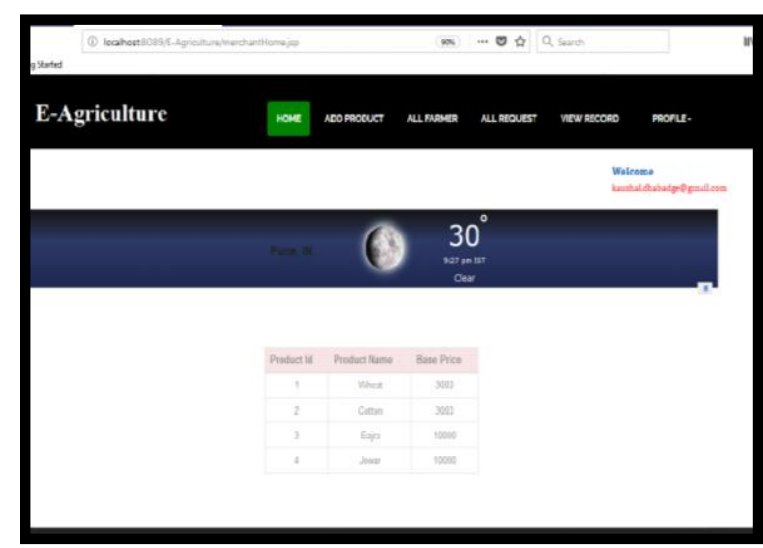

Fig. 2 : Homepage of the system

It shows the transactions done in merchant login. Merchant sends the request to farmers and when farmers accept the request transaction takes place between them. Transaction slip is generated.

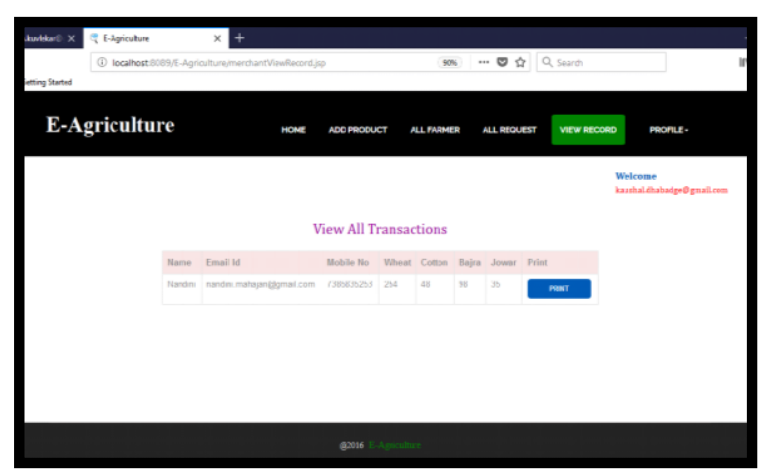

Fig. 3: View all transactions in merchant login.

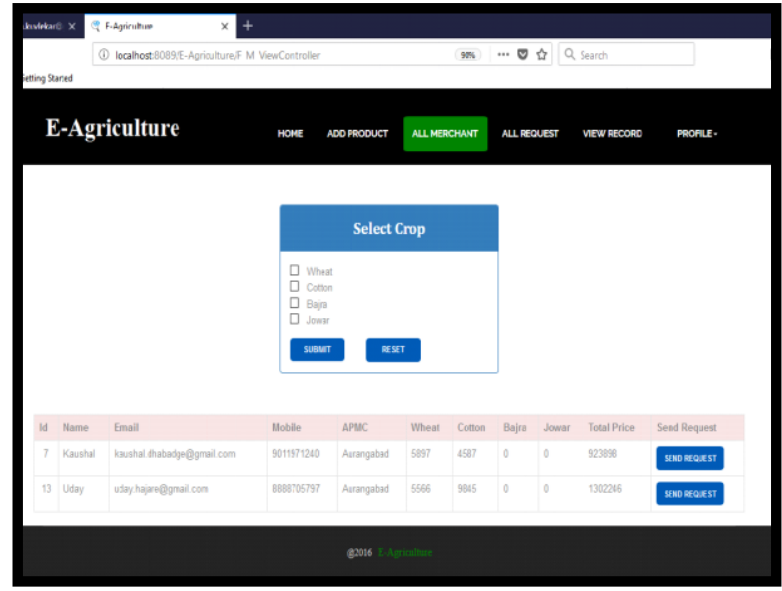

Fig. 4: Merchant Viewed by farmers

In the above figure, after merchant has logged in the module, he can select the crops he wishes to buy. On selecting the crops, all the farmers along with their details. Farmer's products and quantity is displayed. Send request is used to send request for initialization of transaction. Merchant is able to view all the farmers based on crop selection.

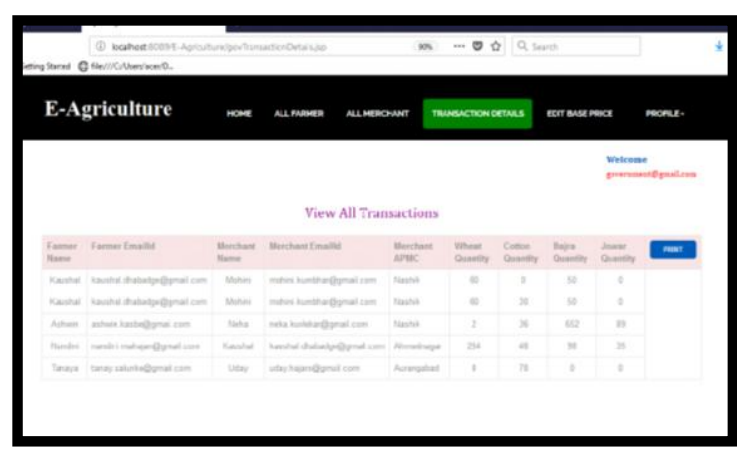

Fig. 5: transactions between farmer and merchant

Above figure shows all the transactions between farmer and merchant after selling crops to the merchant containing various fields i.e. Farmer's name, farmer's email ID, merchant's name, APMC. This is government module view.

\section{CONCLUSION}

In this paper, we have exhibited E-Business in Agriculture for effective communication between Merchants and Farmers for providing more help to all farmers and to stop black marketing. This project will be helpful for farmers to know more about market information. The site will guide the farmers in all the aspects, the current market rate of different products and the earned profit for the sold products, access to the new farming techniques through E-learning and centralized approach to view different government's agriculture schemes including the compensation schemes for farming. The main approach of this project is to prohibit the black marketing of the granary products. The government authorize person has easy see the whole transactions between the farmer and the merchant.

\section{FUTURE SCOPE}

The proposed model act clearly defines business logic which is going to be adopted by all the markets spread across the country. There is no doubt that in any marketing there is motive towards profit involved and at the same time marketing tool based on certain values, principles and faireprices to the farmers to toil hard to till. Through this system we can make sure it is profitable for both farmers and 
consumers. This application will be one such strategy that will encourage the farmers to continue farming and make sure they get the right fruit for the labour.

\section{ACKNOWLEDGMENTS}

It gives us great pleasure in presenting the paper on topic 'EBusiness in Agriculture for effective communication between Merchants and Farmers.' We wish to thank many peoples who have extended their kind cooperation and guidance and have made this presentation success. We would like to take this opportunity to thank our internal guide Prof. Ganesh Deshmukh for giving us all the help and guidance we needed and keen interest inspired us to complete our presentation in a successful manner. We are really grateful to Dr. Ajay M. Fulambarkar (Principal, PCCOE) and Dr. K. Rajeswari, Head of Department of Computer Engineering

\section{REFERENCES}

[1] Manav Singhal, Kshitij Verma, Anupam Shukla, "Krishi Ville - Android based Solution for Indian Agriculture," Advanced

[2] Saurabh A. Ghogare, Priyanka M. Monga, "EAgriculture" Introduction and Figuration of its Application," International Journal of Advanced Research in Computer Science and Software Engineering, Volume 5, Issue 1, January 2015.

[3] L. Pradhan, B. B. Mohapatra, Fakir Mohan, "Eagriculture: A Golden Opportunity for Indian Farmers," International Journal of Research and Development - A Management Review (IJRDMR), Volume-4, Issue-1, 2015.

[4] Soumalya Ghosh, A. B. Garg, Sayan Sarcar, P.S.V.S Sridhar, Ojasvi Maleyvar, and Raveesh kapoor, "KrishiBharati: An Interface for Indian Farmer". Proceeding of the 2014 IEEE Students' Technology Symposium.
[5] D. Vinoth, K. Nisharth and K. Shanmugapriya, "Eagro Crop Marketing for Farming Community". International Journal in Foundations of Computer Science \& Technology (IJFCST), Vol.5, No.2, March 2015.

[6] Sindhu M R, Aditya Pabshettiwar, Ketan.K.Ghumatkar, Pravin.H.Budhehalkar, Paresh.V.Jaju, "E FARMING". Sindhu M R et al, / (IJCSIT) International Journal of Computer Science and Information Technologies, Vol. 3 (2), 2012, 3479-3482.

[7] Sumitha Thankachan, S. Kirubakaran, "E-Agriculture Information Management System". International Journal of Computer Science and Mobile Computing - IJCSMC Vol.3, No. 5, 2014

[8] Ghodke Tushar D., Devde Nitin N., Agwan Sagar C., Kudal Yogesh, "E-Farming : An Innovative Approach for an Indian Farmer ". International Journal on Recent and Innovation Trends in Computing and Communication, Volume: 3 Issue: 9, September 2015.

[9] Nilesh Dumbre, Omkar Chikane, Gitesh More, "System for Agriculture Recommendation Using Data Mining". International Education \& Research Journal (IERJ), EISSN: 2454-9916, Vol: 1, Issue: 5, Dec 2015.

[10] Deshpande Radhika, Bhalekar Dipali, Mutkule Prasad, Nawale Akshay, Sanjay Pandhare, PhD, "One Stop Solution for Farmer Consumer Interaction”. International Journal of Computer Applications (0975 - 8887), National Conference on Advances in Computing (NCAC 2015).

[11] Ashutosh Kumar Tripathi, "Agricultural Price Policy, Output, and Farm Profitability-Examining Linkages during Post-Reform Period in India”. Asian Journal of Agriculture and Development, Vol. 10, No. 1.

[12] Agricultural Marketing S.S. Acharya ISBN - 81-7188387-7 Pages-259. 